\title{
Estimation of daily intake of polychlorinated biphenyls not similar to dioxins (NDL-PCB) from fish consumption in Spain in different population groups
}

\author{
Maria Morales-Suárez-Varela ${ }^{1,2, *}$, Nuria Lopez Santana ${ }^{1}$, Pedro Marti Requena ${ }^{3}$, \\ $M^{a}$ Isabel Beser Santos ${ }^{3}$, Isabel Peraita-Costa ${ }^{1}$ and Agustin Llopis-Gonzalez ${ }^{1,2}$ \\ ${ }^{1}$ Public Health and Environmental Care Unit, Department of Preventive Medicine and Public Health, University of \\ Valencia, Av. Vicente Andrés Estellés s/n, Burjassot 46100, Spain: ${ }^{2}$ CIBER of Epidemiology and Public Health \\ (CIBERESP), Madrid, Spain: ${ }^{3}$ Laboratorio de Salud Pública, Consellería de Sanidad Universal y Salud Pública de la \\ Generalitat Valenciana, Valencia, Spain
}

Submitted 13 February 2018: Final revision received 1 June 2018: Accepted 13 July 2018: First published online 5 September 2018

\begin{abstract}
Objective: To assess the daily intake of polychlorinated biphenyls not similar to dioxins (NDL-PCB) derived from fish consumption in Spain and compare it with tolerance limits in order to establish a safe threshold so that the nutritional benefits derived from fish consumption may be optimized.

Design: Analysis of NDL-PCB in fish samples and ecological study of the estimated intake of NDL-PCB from fish consumption in different Spanish population groups. Subjects: National representative sample of the Spanish population.

Results: The intake of NDL-PCB was estimated in two different scenarios: upper bound (UB) and lower bound (LB). Estimating intake using the average concentration of NDL-PCB found in the fish samples, the intake for 'other children' is estimated as: 1.80 (UB) and $5.33(\mathrm{LB}) \mathrm{ng} / \mathrm{kg}$ per $\mathrm{d}$ at the 50 th percentile (P50); 7.39 (UB) and 21.94 (LB) $\mathrm{ng} / \mathrm{kg}$ per $\mathrm{d}$ at the 95 th percentile (P95) of fish consumption. Estimated NDL-PCB intake shoots up in the toddler group, reaching values of 30.43 (UB) and 90.37 (LB) $\mathrm{ng} / \mathrm{kg}$ per $\mathrm{d}$ at P95. Estimated intake values are lower than those previously estimated in Europe, something expected since in previous studies intake was estimated through total diet. In adults, our estimated values are 1.59 (UB) and $4.72(\mathrm{LB}) \mathrm{ng} / \mathrm{kg}$ per $\mathrm{d}$ at P50; 4.95 (UB) and 14.72 (LB) $\mathrm{ng} / \mathrm{kg}$ per d at P95.

Conclusions: NDL-PCB concentration in fish is under the tolerance limits in most samples. However, daily intake in consumers of large quantities of fish should be monitored and special attention should be given to the youngest age groups due to their special vulnerability and higher exposure.
\end{abstract}

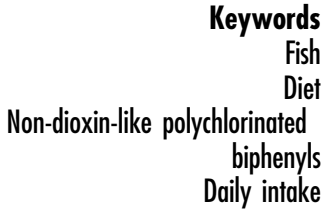

Fish is a key food in a well-balanced diet. It is the best dietary source of two long-chain $n$-3 PUFA, namely DHA and EPA, and is rich in high-quality proteins, essential metals such as $\mathrm{Se}, \mathrm{Mn}$ and $\mathrm{Cu}$, and vitamins ${ }^{(1)}$. Intakes of DHA and EPA $n-3$ PUFA have been linked to low rates of death from $\mathrm{CHD}^{(2)}$. DHA and EPA intakes have also been found to be important for neurodevelopment during pregnancy and childhood ${ }^{(3,4)}$ as well as related to plasma biomarkers that reflect lower levels of inflammation and endothelial activation in CVD and other chronic and acute diseases, including chronic disease kidney disease, sepsis and acute pancreatitis ${ }^{(5)}$.

On the other hand, there has been concern about the potential harm from certain contaminants found in fish, such as polychlorinated biphenyls (PCB) not similar to dioxins (NDL-PCB), which are synthetic organochlorine compounds previously used in industrial and commercial processes $^{(6)}$. They are considered persistent organic pollutants due to properties such as their high chemical and biological stability and great lipophilicity ${ }^{(7)}$.

The European Food Safety Authority assesses the contamination of NDL-PCB by analysing PCB congeners 28, $52,101,138,153$ and 180, which account for $50 \%$ of the 209 total congeners. Normally, for the assessment of total NDL-PCB, the six previously indicated congeners are used as indicators ${ }^{(8)}$.

As for the health effects of these pollutants, few studies are currently available. The International Agency for 
Research on Cancer classified PCB in Group 2A (probably carcinogenic to humans), based on limited evidence in human subjects and sufficient evidence from animal studies ${ }^{(9)}$. This carcinogenicity may possibly be related to the effects on the aryl hydrocarbon receptor, a transcription factor that affects gene expression ${ }^{(10,11)}$. In addition, prenatal (but not postnatal) exposure to PCB and dioxins has been associated with deficits in childhood neurological development ${ }^{(12-14)}$. There are some studies that relate PCB exposure to some other effects like skin abnormalities, deficiencies of the immune system in breast-fed infants, thyroid disorders and others ${ }^{(15-17)}$.

It is very difficult to isolate the effects produced only by NDL-PCB, because there is an overlap of exposures with PCB similar to dioxins (DL-PCB) and polychlorinated dibenzo- $p$-dioxins/polychlorinated dibenzofurans (PCDD/ PCDF) whose effects are difficult to separate, so it is not known what effect corresponds to each of the compounds independently. This makes the toxicological database too limited to allow the establishment of a health-based reference value for NDL-PCB ${ }^{(8)}$.

Although a Tolerable Daily Intake (TDI) for NDL-PCB from fish is still not defined, the TDI for PCB that is used internationally, and which is proposed in the studies by Tryphonas et al. ${ }^{(18,19)}$ and Arnold et $a l^{(20,21)}$, is $20 \mathrm{ng} / \mathrm{kg}$ per $\mathrm{d}$ for the 209 congeners of NDL-PCB, as confirmed by the Agency for Toxic Substances and Disease Registry in 2000.

The aim of the present study was to assess the daily intake of NDL-PCB from the consumption of fish in Spain. For this purpose, the intake of fish in the Spanish population was stratified at the 5th percentile (P5), 50th percentile (P50) and 95th percentile (P95) for different population groups: toddlers, other children, adolescents and adults. The concentration of NDL-PCB in samples of fish taken between 2013 and 2016 in the Comunitat Valenciana was also analysed and stratified at P5, P50 and P95. Based on the concentration of NDL-PCB identified in the fish analysed and the fish consumption of each population group, the intake of these contaminants was estimated in two different scenarios: upper bound (UB) and lower bound (LB). Finally, these estimates were compared with the tolerance limits so that a safe threshold for consumption of fish may be established and the nutritional benefits of this can be obtained in the diet.

\section{Material and methods}

\section{Dietary intake}

Fish consumption data come from a 2005 populationbased nutrition survey in the case of adolescents and other children; the Spanish Agency for Food Safety's FIAB Survey in the case of adults; and the Food Patterns of Spanish Schoolchildren and Adolescents in the case of the toddlers. The sample of adults includes people over 18 years old, the adolescent sample those from 11 to 18 years of age, the sample of other children includes children from 4 to 10 years of age, and the sample of toddlers includes children aged 1 to 3 years. The data pertaining to the P5, P50 and P95 levels of fish consumption were taken to calculate the intake of NDL-PCB in different types of fish-consuming individuals. All data were obtained from the Comprehensive Food Consumption Database of the European Food Safety Authority ${ }^{(22)}$.

\section{Food sampling}

The study took place in Valencian Community region, located in the east and south-east of Spain with about 5 million inhabitants. The average consumption of fish was evaluated in the different regions of the Spanish territory, specifically for the years of the study (2013 to 2016) and these data have been subjected to a means comparison test (ANOVA) between the different regions. A total of eighty-five fish samples were analysed, twenty-two in 2013, twenty-one in 2014, twenty-one in 2015 and twentytwo in 2016. Sampling was carried out by inspectors of the Department of Public Health as dictated by European legislation in ANNEX II of Regulation (EU) No. 252/ $2012^{(23)}$, where random sampling methods for the official control of dioxin (PCDD/PCDF), DL-PCB and NDL-PCB levels are established in certain food products. Samples were taken at randomly selected different local markets of the Valencian Community. The fish species sampled were also selected at random. Samples were packaged in glass, aluminium, polypropylene or polyethylene containers and transported in an ice box. Once in the laboratory they were stored at $-80^{\circ} \mathrm{C}$ until the date of analysis.

\section{Chemical analysis}

Only the edible part of fish was used for the chemical analysis; the entire sample was crushed, homogenized and subsequently frozen at $-17^{\circ} \mathrm{C}$ until analysis, taking account of the specific provisions for fish in Regulation (EU) No. $252 / 2012^{(23)}$. Sample analysis was performed by the Public Health Laboratory of Valencia using the in-house method described below.

The extraction solvent was hexane and three successive extraction cycles were carried out. The extract was evaporated to near dryness. The extracts were dissolved in hexane for sample cleaning. Purification was carried out in two stages, using first an acid treatment and subsequently silica columns. The fat was removed by performing an extraction with $96 \%(\mathrm{w} / \mathrm{w})$ sulfuric acid, from which the supernatant was taken and dissolved in $10 \mathrm{ml}$ hexane. After the acid treatment, $1 \mathrm{ml}$ of of the supernatant/hexane sample was loaded into the $500 \mathrm{mg}$ silica column previously conditioned with hexane. The final extract of the sample was evaporated to dryness under a stream of nitrogen, reconstituted by the addition of $0.5 \mathrm{ml}$ hexane and then transferred to two vials with a $250 \mu$ linsert for 
determination by GC-MS/MS. The detection by GC-MS/ MS was performed in a gas chromatograph coupled to a triple-quadrupole mass detector (TSQ Quantum ${ }^{\mathrm{TM}}$, ThermoFisher Scientific) equipped with a DB-XLB column (30 $\mathrm{m}$ length, $0.250 \mathrm{~mm}$ diameter, $0.50 \mu \mathrm{m}$ film thickness) ${ }^{(24,25)}$.

The quantification was done by a calibration curve with internal standard in each sequence of samples, with the results calculated using the formula:

$$
C=\frac{\frac{C_{\mathrm{c}} \times C_{\mathrm{f}} \times V_{\mathrm{i}}}{V_{\mathrm{SPE}}}}{P_{\mathrm{m}}}
$$

where

$$
\begin{aligned}
& C=\text { concentration in the sample }(\mathrm{ng} / \mathrm{g} \text { fresh weight); } \\
& C_{\mathrm{c}}=\text { concentration in the chromatogram }(\mathrm{ng} / \mathrm{ml}) ; \\
& V_{\mathrm{f}}=\text { final volume }(0.5 \mathrm{ml}) ; \\
& V_{\mathrm{i}}=\text { initial volume; } \\
& V_{\mathrm{SPE}}=\text { volume of the aliquot taken for the extraction of } \\
& \text { the solid phase }(2 \mathrm{ml}) ; \text { and } \\
& P_{\mathrm{m}}=\text { weight of the sample taken to perform the analysis. }
\end{aligned}
$$

The concentration of NDL-PCB was expressed in two different scenarios: the LB scenario, which implies that the unquantified results are considered zero; and the UB scenario in which the unquantified results are established as the limit of quantification ${ }^{(26)}$.

\section{Model of exposure estimation}

The dietary intake of NDL-PCB was expressed in nanograms per kilogram of body weight per day. The dietary exposure was estimated with the deterministic method taking into account two different scenarios, UB and LB, within each population group, combining the consumption of fish in grams per kilogram of body weight per day at P5, P50 and P95, thus considering the percentile stratified in different population groups (adults, adolescents, children and toddlers), with the P5, P50 and P95 that are calculated according to the concentration of the sum of the NDL-PCB indicators in the fish samples analysed. In this way we are able to estimate the level of contaminants to which the population may be exposed according to their level of fish consumption, high (P95), medium (P50) or low (P5), also taking account of the contamination of the fish as high (P95), medium (P50) or low (P5).

The estimation of the daily intake of the contaminant was made using the formula:

$$
E i=\Sigma T p \times C p,
$$

where

$E i=$ estimated intake of NDL-PCB;

$\Sigma T p=$ sum of the concentration of NDL-PCB indicators in fish in each scenario; and

$C P=$ consumption of fish in each scenario.

It was calculated whether there are significant differences between the two possible scenarios for all population groups and percentiles. They were compared using ANOVA with $95 \%$ confidence level $(P<0 \cdot 05)$.

\section{Risk assessment}

Once the dietary intake of NDL-PCB was estimated, the risk that the estimated intake exceeded the tolerance limits was calculated. Taking into account that studies by Tryphonas et al. ${ }^{(18,19)}$ and Arnold et al. ${ }^{(20,21)}$ stipulate the limit at $20 \mathrm{ng} / \mathrm{kg}$ per $\mathrm{d}$ for the 209 congeners, and that the congeners included in the present study represent $50 \%{ }^{(8)}$, the value obtained should not exceed $10 \mathrm{ng} / \mathrm{kg}$ per $\mathrm{d}$. The probability of not exceeding this value with a $95 \%$ CI was calculated using the formulas:

$$
P=\frac{E i_{\mathrm{PCB}}}{\mathrm{TDI}}
$$

and

$$
95 \% \mathrm{CI}=p \pm \sqrt{\frac{p \times q}{n}},
$$

where

$$
\begin{aligned}
& p=\text { probability of the event studied; } \\
& q=(1-p) ; \text { and } \\
& n=\text { sample size. }
\end{aligned}
$$

As in the exposure model, it was calculated whether there are significant differences between the two possible scenarios in the risk analysis. They were compared with the $\chi^{2}$ test with $95 \%$ confidence level $(P<0.05)$. The statistical software package IBM SPSS Statistics version 22 was used for the analysis.

\section{Results}

When comparing the fish consumption means for the years 2013 to 2016 in the different regions of the Spanish territory, we found that there were no statistically significant differences in the total fish consumed $(P=0.777)$.

Table 1 shows all the different fish species sampled, the median concentration of PCB (ng/g) for each species and the extractive fishing zone from which each species was obtained.

Table 2 shows the daily intake of NDL-PCB classified according to the P5, P50 and P95 of fish intake combined with the P5, P50 and P95 of the concentration of the sum of NDL-PCB indicators. This allows us to estimate nine possible scenarios in UB and another nine in $\mathrm{LB}$, resulting from crossing the percentiles of fish intake with those of NDL-PCB concentration.

It can be observed that those population groups that consume low amounts of fish (P5) are exposed to undetectable amounts of NDL-PCB, but as the intake of fish increases, the intake of NDL-PCB also increases.

Total estimated daily intake of NDL-PCB in P50 of fish consumption in adults ranges between 0.00 and $3.92 \mathrm{ng} / \mathrm{kg}$ 
Table 1 Analysed fish and capture origins

\begin{tabular}{|c|c|c|c|}
\hline Common name & Scientific name & $\begin{array}{l}\text { Median concentration, } \\
\text { total sum of PCB }(\mathrm{ng} / \mathrm{g})\end{array}$ & Capture origin \\
\hline Albacore tuna & Thunus alalunga & $6 \cdot 40$ & $\begin{array}{l}\text { FAO } 34 \\
\text { FAO } 27 \\
\text { FAO } 37\end{array}$ \\
\hline Angler & Lophius piscatorius & 5.02 & FAO 37 \\
\hline Argentine & Argentina sphyraena & $8 \cdot 70$ & FAO 37 \\
\hline Atlantic horse mackerel & Trachurus tracurus & $7 \cdot 60$ & $\begin{array}{l}\text { FAO } 37 \\
\text { FAO } 27\end{array}$ \\
\hline Atlantic mackerel & Scomber scombrus & $4 \cdot 20$ & FAO 27 \\
\hline Black marlin & Makaira indica & $4 \cdot 20$ & FAO 57 \\
\hline Blue whiting & Micromesistius poutassou & $4 \cdot 20$ & FAO 27 \\
\hline Bogue & Boops boops & 5.40 & FAO 37 \\
\hline Calamari & Loligo gahi & 4.20 & FAO 51 \\
\hline Codfish & Gadus morhua & $4 \cdot 20$ & FAO 27 \\
\hline Common cuttlefish & Sepia officinalis & $4 \cdot 20$ & FAO 34 \\
\hline Common pandora & Pagelus erythrinus & $6 \cdot 10$ & FAO 37 \\
\hline European anchovy & Engraulis encrasicolus & $12 \cdot 75$ & FAO 37 \\
\hline European hake & Merluccius merluccius & $6 \cdot 20$ & $\begin{array}{l}\text { FAO } 27 \\
\text { FAO } 37 \\
\text { FAO } 41 \\
\text { FAO } 47\end{array}$ \\
\hline European pilchard & Sardina pilchardus & 11.00 & $\begin{array}{l}\text { FAO } 37 \\
\text { FAO } 27\end{array}$ \\
\hline European seabass & Dicentrarchus labrax & 4.60 & $\begin{array}{c}\text { Aquaculture. Spain } \\
\text { FAO } 37\end{array}$ \\
\hline Flathead mullet & Mugil cephalus & 4.70 & FAO 37 \\
\hline Gilt-head seabream & Sparus aurata & $7 \cdot 10$ & $\begin{array}{l}\text { FAO } 37 \\
\text { FAO } 34\end{array}$ \\
\hline Greater forkbeard & Phicis blennoides & $4 \cdot 20$ & FAO 37 \\
\hline Mediterranean mussel & Mytilus galloprovincialis & 8.80 & FAO 37 \\
\hline Pacific chub mackerel & Scomber japonicus & $15 \cdot 50$ & FAO 27 \\
\hline Pink cuttlefish & Sepia orbignyana & $5 \cdot 35$ & FAO 37 \\
\hline Poor cod & Trisopterus minutus & 8.40 & FAO 37 \\
\hline Rainbow trout & Oncorhynchus mykiss & 4.38 & Aquaculture. Spain \\
\hline Red mullet & Mullus barbatus & 44.80 & FAO 37 \\
\hline Salmon & Salmo salar & 5.56 & FAO 27 \\
\hline Sea robin & Triglidae spp. & $6 \cdot 90$ & FAO 27 \\
\hline Striped catfish & Pangasius hypophthalmus & $6 \cdot 30$ & FAO 61 \\
\hline Swordfish & Xiphias gladius & $4 \cdot 20$ & $\begin{array}{l}\text { FAO } 27 \\
\text { FAO } 51 \\
\text { FAO } 77\end{array}$ \\
\hline
\end{tabular}

PCB, polychlorinated biphenyl.

per $\mathrm{d}$ for fish with a low concentration of NDL-PCB and between 1.59 and $4.72 \mathrm{ng} / \mathrm{kg} / \mathrm{d}$ for fish with medium concentration of NDL-PCB. In these two cases there are significant differences between the UB and LB scenarios $(P=0.001$ and $P=0.010$, respectively). For fish with a high concentration of NDL-PCB, the estimated daily intake, between 16.78 and $18.09 \mathrm{ng} / \mathrm{kg}$ per $\mathrm{d}$ for $\mathrm{LB}$ and $\mathrm{UB}$, is not significantly different $(P=0 \cdot 510)$.

In adolescents, in $\mathrm{P} 50$ of fish consumption, the total estimated daily intake of NDL-PCB ranges between 0.00 and $2.37 \mathrm{ng} / \mathrm{kg}$ per $\mathrm{d}$ for fish with a low concentration of NDL-PCB, between 0.96 and $2.85 \mathrm{ng} / \mathrm{kg}$ per $\mathrm{d}$ for fish with a medium concentration of NDL-PCB, and between 10.14 and $10.93 \mathrm{ng} / \mathrm{kg}$ per $\mathrm{d}$ for fish with a high concentration of NDL-PCB. There are significant differences between UB and LB scenarios for consumption of fish with low $(P=0.001)$ and medium concentrations of NDL-PCB $(P=0.002)$, but not for consumption of fish with high NDL-PCB concentration $(P=0.555)$.
For other children, the total estimated daily intake of NDL-PCB in P50 of fish consumption ranges between 0.00 and $4.44 \mathrm{ng} / \mathrm{kg}$ per $\mathrm{d}$ for fish with a low concentration of NDL-PCB, between 1.80 and $5.33 \mathrm{ng} / \mathrm{kg}$ per $\mathrm{d}$ for fish with a medium concentration of NDL-PCB, and between 18.98 and $20.46 \mathrm{ng} / \mathrm{kg}$ per $\mathrm{d}$ for fish with a high concentration of NDL-PCB. In this case, there are significant differences between UB and LB scenarios for consumption of fish with low concentration of NDL-PCB $(P=0.001)$ and medium concentration of NDL-PCB $(P=0.007)$ that do not exist for consumption of fish with high NDL-PCB concentration $(P=0.594)$.

In the toddler group, the total estimated daily intake of NDL-PCB from fish at the P50 consumption level is negligible.

In the case of intake of NDL-PCB from fish consumption at the P95 level, an increase is observed as age of the study subjects decreases, except for the adolescents group. In adults, intake ranges from 0.00 to $12.24 \mathrm{ng} / \mathrm{kg}$ per $\mathrm{d}$ for fish with a low concentration of NDL-PCB and between 
Table 2 Estimated daily intake (ng/kg per d) of polychlorinated biphenyls not similar to dioxins (NDL-PCBs) from fish consumption in Spain in different population groups, 2013 to 2016

\begin{tabular}{|c|c|c|c|c|}
\hline \multirow[b]{2}{*}{ Adults } & & \multicolumn{3}{|c|}{ Daily intake of fish $(\mathrm{g} / \mathrm{kg}$ per $\mathrm{d})$} \\
\hline & & P5 $(0.00)$ & P50 (0.93) & P95 (2.91) \\
\hline \multirow[t]{3}{*}{ Concentration of the sum of NDL-PCB (ng/g) (LB) } & P5 (4.20) & 0.00 & 3.92 & $12 \cdot 24$ \\
\hline & P50 (5.05) & 0.00 & 4.72 & 14.72 \\
\hline & P95 (19.37) & 0.00 & 18.09 & $56 \cdot 46$ \\
\hline \multirow[t]{4}{*}{ Concentration of the sum of NDL-PCB (ng/g) (UB) } & P5 (0.00) & 0.00 & 0.00 & 0.00 \\
\hline & P50 (1.70) & 0.00 & 1.59 & 4.95 \\
\hline & P95 (17.97) & 0.00 & $16 \cdot 78$ & $52 \cdot 38$ \\
\hline & & \multicolumn{3}{|c|}{ Daily intake of fish ( $\mathrm{g} / \mathrm{kg}$ per $\mathrm{d})$} \\
\hline \multicolumn{2}{|l|}{ Adolescents } & P5 $(0.00)$ & P50 (0.56) & P95 (2.75) \\
\hline \multirow[t]{3}{*}{ Concentration of the sum of NDL-PCB (ng/g) (LB) } & P5 (4.20) & 0.00 & $2 \cdot 37$ & 11.54 \\
\hline & P50 (5.05) & 0.00 & $2 \cdot 85$ & $13 \cdot 88$ \\
\hline & P95 (19.37) & 0.00 & 10.93 & $53 \cdot 24$ \\
\hline \multirow[t]{4}{*}{ Concentration of the sum of NDL-PCB (ng/g) (UB) } & P5 (0.00) & 0.00 & 0.00 & 0.00 \\
\hline & P50 (1.70) & 0.00 & 0.96 & 4.67 \\
\hline & P95 (17.98) & 0.00 & $10 \cdot 14$ & $49 \cdot 30$ \\
\hline & & \multicolumn{3}{|c|}{ Daily intake of fish $(\mathrm{g} / \mathrm{kg}$ per $\mathrm{d})$} \\
\hline \multicolumn{2}{|l|}{ Other children } & P5 $(0.00)$ & P50 (1.06) & P95 (4.35) \\
\hline \multirow[t]{3}{*}{ Concentration of the sum of NDL-PCB (ng/g) (LB) } & P5 (4.20) & 0.00 & 4.44 & $18 \cdot 25$ \\
\hline & P50 (5.05) & 0.00 & $5 \cdot 33$ & 21.94 \\
\hline & P95 (19.37) & 0.00 & $20 \cdot 46$ & 84.19 \\
\hline \multirow[t]{4}{*}{ Concentration of the sum of NDL-PCB (ng/g) (UB) } & P5 (0.00) & 0.00 & 0.00 & 0.00 \\
\hline & P50 (1.70) & 0.00 & $1 \cdot 80$ & $7 \cdot 39$ \\
\hline & P95 (17.98) & 0.00 & $18 \cdot 98$ & $78 \cdot 10$ \\
\hline & & \multicolumn{3}{|c|}{ Daily intake of fish ( $\mathrm{g} / \mathrm{kg}$ per $\mathrm{d})$} \\
\hline \multicolumn{2}{|l|}{ Toddlers } & P5 $(0.00)$ & P50 (0.00) & P95 (17.89) \\
\hline \multirow[t]{3}{*}{ Concentration of the sum of NDL-PCB (ng/g) (LB) } & P5 (4.20) & 0.00 & 0.00 & $75 \cdot 16$ \\
\hline & P50 (5.05) & 0.00 & 0.00 & $90 \cdot 37$ \\
\hline & P95 (19.37) & 0.00 & 0.00 & 346.71 \\
\hline \multirow{3}{*}{ Concentration of the sum of NDL-PCB (ng/g) (UB) } & P5 (0.00) & 0.00 & 0.00 & 0.00 \\
\hline & P50 (1.70) & 0.00 & 0.00 & 30.42 \\
\hline & P95 (17.98) & 0.00 & 0.00 & 321.66 \\
\hline
\end{tabular}

P5, 5th percentile; P50, 50th percentile; P95, 95th percentile; LB, lower bound; UB, upper bound.

4.95 and $14.72 \mathrm{ng} / \mathrm{kg}$ per $\mathrm{d}$ for fish with medium NDL-PCB concentration. In these two cases there are significant differences between the UB and LB scenarios, since $P=0.001$ in both cases. On the contrary, in the case of fish with a high concentration of NDL-PCB, where NDL-PBD intake is 52.98 and $56.46 \mathrm{ng} / \mathrm{kg}$ per $\mathrm{d}$, there are no significant differences between LB and UB $(P=0 \cdot 130)$.

In adolescents, in $\mathrm{P} 95$ of fish consumption, the total estimated daily intake of NDL-PCB ranges between 0.00 and $11.54 \mathrm{ng} / \mathrm{kg}$ per $\mathrm{d}$ for fish with a low concentration of NDL-PCB, between 4.67 and $13.88 \mathrm{ng} / \mathrm{kg}$ per $\mathrm{d}$ for fish with a medium concentration of NDL-PCB, and between 49.30 and $53.24 \mathrm{ng} / \mathrm{kg}$ per $\mathrm{d}$ for fish with a high concentration of NDL-PCB. In the same way as in the adults, there are significant differences between UB and LB scenarios for consumption of fish with low $(P=0.001)$ and medium concentrations of NDL-PCB $(P=0 \cdot 001)$ and no significant difference for consumption of fish with high NDL-PCB concentration $(P=0 \cdot 086)$.
With respect to the group of other children, the total estimated daily intake of NDL-PCB ranges between $0 \cdot 00$ and $18.25 \mathrm{ng} / \mathrm{kg}$ per $\mathrm{d}$ for fish with a low concentration of NDL-PCB, between 7.39 and $21.94 \mathrm{ng} / \mathrm{kg}$ per $\mathrm{d}$ for fish with a medium concentration of NDL-PCB, and between 78.10 and $84.19 \mathrm{ng} / \mathrm{kg}$ per d for fish with a high concentration of NDL-PCB, at the P95 level of fish consumption. There are significant differences between UB and LB scenarios for consumption of fish with low $(P=0.001)$, medium $(P=0.001)$ and high concentrations of NDL-PCB $(P=0 \cdot 049)$.

Finally, in the case of the toddlers with P95 fish consumption level, their total estimated daily intake of NDLPCB ranges between 0.00 and $75 \cdot 16 \mathrm{ng} / \mathrm{kg}$ per $\mathrm{d}$ for fish with a low concentration of NDL-PCB, between $30 \cdot 42$ and $90.37 \mathrm{ng} / \mathrm{kg}$ per $\mathrm{d}$ for fish with a medium concentration of NDL-PCB, and between 321.66 and $346.71 \mathrm{ng} / \mathrm{kg}$ per $\mathrm{d}$ for fish with a high concentration of NDL-PCB. As in the previous cases, there are significant differences between 
Table 3 Risk of intake above the Tolerable Daily Intake (TDI) for polychlorinated biphenyls not similar to dioxins (NDL-PCBs) from fish consumption in Spain, with $95 \% \mathrm{Cl}$, in different population groups, 2013 to 2016

\begin{tabular}{|c|c|c|c|c|c|c|c|}
\hline \multirow[b]{3}{*}{ Adults } & & \multicolumn{6}{|c|}{ Daily intake of fish ( $\mathrm{g} / \mathrm{kg}$ per $\mathrm{d})$} \\
\hline & & \multicolumn{2}{|c|}{ P5 $(0.00)$} & \multicolumn{2}{|c|}{ P50 (0.93) } & \multicolumn{2}{|c|}{ P95 (2.91) } \\
\hline & & TDI & $95 \% \mathrm{Cl}$ & TDI & $95 \% \mathrm{Cl}$ & TDI & $95 \% \mathrm{Cl}$ \\
\hline \multirow[t]{3}{*}{ Concentration of the sum of NDL-PCB (ng/g) (LB) } & P5 (4.20) & 0.00 & $0.00,0.00$ & 0.00 & $0.00,0.00$ & 0.00 & $0.00,0.00$ \\
\hline & P50 (5.05) & 0.00 & $0.00,0.00$ & 0.16 & $0.14,0.18$ & 0.50 & $0.46,0.53$ \\
\hline & P95 (19.37) & 0.00 & $0.00,0.00$ & 1.68 & $1.61,1.75$ & $5 \cdot 24$ & $4.94,5.53$ \\
\hline \multirow[t]{5}{*}{ Concentration of the sum of NDL-PCB (ng/g) (UB) } & P5 $(0.00)$ & 0.00 & $0.00,0.00$ & 0.39 & $0.36,0.42$ & 1.22 & $1 \cdot 19,126$ \\
\hline & P50 (1.70) & 0.00 & $0.00,0.00$ & 0.47 & $0.44,0.50$ & 1.47 & $1.42,1.52$ \\
\hline & P95 (17.97) & 0.00 & $0.00,0.00$ & $1 \cdot 81$ & $1 \cdot 73,1.89$ & $5 \cdot 65$ & $5 \cdot 33,5 \cdot 97$ \\
\hline & & \multicolumn{6}{|c|}{ Daily intake of fish ( $\mathrm{g} / \mathrm{kg}$ per $\mathrm{d})$} \\
\hline & & \multicolumn{2}{|c|}{ P5 $(0.00)$} & \multicolumn{2}{|c|}{ P50 (0.56) } & \multicolumn{2}{|c|}{ P95 (2.75) } \\
\hline Adolescents & & TDI & $95 \% \mathrm{Cl}$ & TDI & $95 \% \mathrm{Cl}$ & TDI & $95 \% \mathrm{Cl}$ \\
\hline \multirow[t]{3}{*}{ Concentration of the sum of NDL-PCB (ng/g) (LB) } & P5 (4.20) & 0.00 & $0.00,0.00$ & 0.00 & $0.00,0.00$ & 0.00 & $0.00,0.00$ \\
\hline & P50 (5.05) & 0.00 & $0.00,0.00$ & 0.10 & $0.07,0.12$ & 0.47 & $0.43,0.51$ \\
\hline & P95 (19.37) & 0.00 & $0.00,0.00$ & 1.01 & $1.01,1.02$ & 4.94 & $4 \cdot 60,5 \cdot 28$ \\
\hline \multirow[t]{5}{*}{ Concentration of the sum of NDL-PCB (ng/g) (UB) } & P5 $(0.00)$ & 0.00 & $0.00,0.00$ & 0.24 & $0.20,0.27$ & $1 \cdot 15$ & $1 \cdot 12,1 \cdot 19$ \\
\hline & P50 (1.70) & 0.00 & $0.00,0.00$ & 0.29 & $0.25,0.32$ & 1.39 & $1.33,1.44$ \\
\hline & P95 (17.97) & 0.00 & $0.00,0.00$ & 1.09 & $1 \cdot 07,1 \cdot 12$ & $5 \cdot 32$ & $4.96,5.69$ \\
\hline & & \multicolumn{6}{|c|}{ Daily intake of fish ( $\mathrm{g} / \mathrm{kg}$ per $\mathrm{d})$} \\
\hline & & \multicolumn{2}{|c|}{ P5 (0.00) } & \multicolumn{2}{|c|}{ P50 (1.06) } & \multicolumn{2}{|c|}{ P95 (4.35) } \\
\hline Other children & & TDI & $95 \% \mathrm{Cl}$ & TDI & $95 \% \mathrm{Cl}$ & TDI & $95 \% \mathrm{Cl}$ \\
\hline \multirow[t]{3}{*}{ Concentration of the sum of NDL-PCB (ng/g) (LB) } & P5 (4.20) & 0.00 & $0.00,0.00$ & 0.00 & $0.00,0.00$ & 0.00 & $0.00,0.00$ \\
\hline & P50 (5.05) & 0.00 & $0.00,0.00$ & 0.18 & $0.14,0.21$ & 0.74 & $0.70,0.78$ \\
\hline & P95 (19.37) & 0.00 & $0.00,0.00$ & 1.90 & $1 \cdot 77,2 \cdot 03$ & $7 \cdot 81$ & $7.09,8.53$ \\
\hline \multirow[t]{5}{*}{ Concentration of the sum of NDL-PCB (ng/g) (UB) } & P5 (0.00) & 0.00 & $0.00,0.00$ & 0.44 & $0.39,0.49$ & 1.82 & $1.70,1.95$ \\
\hline & P50 (1.70) & 0.00 & $0.00,0.00$ & 0.53 & $0.48,0.58$ & $2 \cdot 19$ & $2 \cdot 04,2 \cdot 35$ \\
\hline & P95 (17.97) & 0.00 & $2 \cdot 04,2 \cdot 35$ & $2 \cdot 05$ & $1 \cdot 90,2 \cdot 19$ & 8.42 & $1 \cdot 90,2 \cdot 19$ \\
\hline & & \multicolumn{6}{|c|}{ Daily intake of fish ( $\mathrm{g} / \mathrm{kg}$ per $\mathrm{d}$ ) } \\
\hline & & \multicolumn{2}{|c|}{ P5 $(0.00)$} & \multicolumn{2}{|c|}{ P50 (0.00) } & \multicolumn{2}{|c|}{ P95 (17.89) } \\
\hline Toddlers & & TDI & $95 \% \mathrm{Cl}$ & TDI & $95 \% \mathrm{Cl}$ & TDI & $95 \% \mathrm{Cl}$ \\
\hline \multirow[t]{3}{*}{ Concentration of the sum of NDL-PCB (ng/g) (LB) } & P5 (4.20) & 0.00 & $0.00,0.00$ & 0.00 & $0.00,0.00$ & 0.00 & $0.00,0.00$ \\
\hline & P50 (5.05) & 0.00 & $0.00,0.00$ & 0.00 & $0.00,0.00$ & 3.04 & $1 \cdot 86,4 \cdot 23$ \\
\hline & P95 (19.37) & 0.00 & $0.00,0.00$ & 0.00 & $0.00,0.00$ & $32 \cdot 17$ & $17 \cdot 11,47 \cdot 22$ \\
\hline \multirow{3}{*}{ Concentration of the sum of NDL-PCB (ng/g) (UB) } & P5 $(0.00)$ & 0.00 & $0.00,0.00$ & 0.00 & $0.00,0.00$ & 7.52 & $4 \cdot 19,10 \cdot 84$ \\
\hline & P50 (1.70) & 0.00 & $0.00,0.00$ & 0.00 & $0.00,0.00$ & $9 \cdot 04$ & $4.99,13.09$ \\
\hline & P95 (17.97) & 0.00 & $0.00,0.00$ & 0.00 & $0.00,0.00$ & 34.67 & $18.43,50.91$ \\
\hline
\end{tabular}

P5, 5th percentile; P50, 50th percentile; P95, 95th percentile; LB, lower bound; UB, upper bound.

UB and LB scenarios for consumption of fish with low $(P=0.001)$ and medium concentrations of NDL-PCB $(P=0.001)$ and no significant difference for consumption of fish with high NDL-PCB concentration $(P=0 \cdot 710)$.

After this assessment of fish intake based on its potential concentration of NDL-PCB and taking account of the BMI of each group, we identify that the youngest population group, the toddlers, are the ones that present increased exposure to NDL-PCB in the P95 of fish consumption.

Table 3 presents the estimated risk of exceeding the tolerance limits classified according to the P5, P50 and P95 of fish intake combined with the P5, P50 and P95 of the concentration of NDL-PCB indicators. This allows us to estimate nine possible scenarios in UB and another nine in
LB, resulting from crossing the percentiles of fish intake with those of NDL-PCB concentration.

There is no risk of exceeding the consumption tolerance limits of NDL-PCB for groups whose fish consumption is lower than $\mathrm{P} 5$, since they are not exposed to NDL-PCB, but as the consumption of fish increases so too does the intake of NDL-PCB.

At the P50 level of fish consumption in adults, there is a risk that the tolerance limit will be exceeded only when fish with high concentration of NDL-PCB are consumed. The risk is estimated to be between 68 and $81 \%$. In adolescents, at the $\mathrm{P} 50$ level of fish consumption there is also risk only if fish with a high concentration of NDL$\mathrm{PCB}$ are consumed; in this case the risk is $1-5 \%$. For the 
other children group, there is once again risk only when fish with high concentration of NDL-PCB are consumed. In the group of toddlers, there is no risk in any of the cases in this percentile of fish consumption.

In P95 of fish consumption, there are significant differences between UB and LB in all population groups in the case that fish with low concentration of NDL-PCB are consumed $(P<0.005)$. In the UB scenario all groups are at risk (adults $22 \%$, adolescents $15 \%$, other children $82 \%$, toddlers $752 \%$ ) and in the LB scenario none of them is considered at risk. If the fish consumed have medium and high concentrations of NDL-PCB, all groups are again at risk of exceeding tolerance limits. There are no significant differences between UB and LB scenarios when fish with a high concentration of NDL-PCB are consumed in any of the population groups. In contrast, for fish with medium NDL-PCB concentration, there are significant differences in the adolescents group $(P=0.038)$.

\section{Discussion}

The present paper is the first that estimates the intake of NDL-PCB from fish in Spain, in addition to calculating the risk of exceeding tolerance limits. The importance of this is that fish consumption in Spain is one of the main bases of the diet and Spain is one of the countries with the highest fish consumption globally ${ }^{(27)}$. This consumption is widespread throughout the Spanish population; in the Consumer Consumption Database of Households of the Government of Spain ${ }^{(28)}$, it is possible to compare the consumption of fish in the Valencian Community with respect to other communities and the average for Spain, identifying that there are no significant differences. Therefore, using fish consumption data at the national level allows us to know the different scenarios among the Spanish population.

On the other hand, the consumption of fish in Spain is quite homogeneous due to the distribution network, which allows us to consider that the fish analysed are representative of the fish consumed in Spain.

Regarding Table 2, we see that when the age of the population groups decreases the intake of NDL-PCB increases proportionally, less in the case of adolescents that decreases when compared with adults; this is due to the variation in fish intake of each group. This poses a problem, because although the weights of younger populations are lower and therefore the concentration of pollutants consumed is equal to that of the adult population, the effect on these populations will be much greater because their mechanisms of metabolism and elimination of pollutants are less developed; also contributing to a process of future bioaccumulation. This could cause significant health risks for neurological development in this highly vulnerable group; the first years of life being the time where there are more documented problems with neurodevelopment associated with the intake of $\mathrm{PCB}^{(12-14,29,30)}$.

Taking into account the maximum tolerable intake of $10 \mathrm{ng} / \mathrm{kg}$ per d, there are some groups that are at risk due to NDL-PCB, especially the high fish consumers (in all population groups) and the consumers of fish with higher content of NDL-PCB (possibly fish with higher fat concentration, owing to the fact that NDL-PCB, being organic pollutants, tend to accumulate more in fatty tissues ${ }^{(31)}$ ) or from places with greater contamination (since in these places the exposure is greater).

Resulting from the present study, it has been identified that fish consumption at a younger age should be restricted to levels below $17.89 \mathrm{~g} / \mathrm{kg}$ per $\mathrm{d}$ and in adults it would not be advisable to exceed $0.93 \mathrm{~g} / \mathrm{kg}$ per $\mathrm{d}$. While these results may seem strange, in the study, the toddlers who consume fish consume $17.89 \mathrm{~g} / \mathrm{kg}$ per $\mathrm{d}$ and the next step down in consumption estimates that they consume $0 \mathrm{~g}$ fish $/ \mathrm{kg}$ per $\mathrm{d}$. Since these levels are those which suppose a risk, consumption should be lower; but there is no other lower level of intake apart from zero that may be given as safe and recommending a consumption of no fish would not be appropriate. These measures would ensure the positive balance of the nutritional benefits of fish consumption against the health risk posed by the presence of NDL-PCB. Regarding the consumption of $0.93 \mathrm{~g}$ fish $/ \mathrm{kg}$ per $\mathrm{d}$ by adults in the case of fish with low and medium concentrations of NDL-PCB, the exposure is below the tolerable level of NDL-PCB intake (10 ng/g per d) and in the case of fish with high concentration is a bit higher, but we must take into account that all the fish that is consumed will not have a high concentration of NDL-PCB.

If the consumption of fish with low or medium concentration of NDL-PCB is average, that is, about $0.93 \mathrm{~g} / \mathrm{kg}$ per $\mathrm{d}$ in adults, $0.56 \mathrm{~g} / \mathrm{kg}$ per $\mathrm{d}$ in adolescents, $0.44 \mathrm{~g} / \mathrm{kg}$ per $\mathrm{d}$ in other children and $0.00 \mathrm{~g} / \mathrm{kg}$ per $\mathrm{d}$ in toddlers, there is no risk of exceeding the tolerance levels, which means that in these cases the population could benefit from the nutritional properties of the fish. If fish with a high concentration of NDL-PCB is consumed, intake should be reduced since there is a considerable increase in the risk of exceeding tolerance levels in adults (68$81 \%)$ and a smaller, although noteworthy, increase in adolescents (1-5\%). It is important to note that when assessing the intake of NDL-PCB only from fish, the models calculated underestimate the true exposure to NDL-PCB and, therefore, the risk of exceeding tolerable values increases.

The results of the estimated intake of NDL-PCB calculated in the present study can be compared with other studies conducted in Europe, but the estimated intakes in different countries are calculated from the consumption of various foods that make up the usual diet, not just fish. In Italy, the study in 2008 by Fattore et $a l .{ }^{(32)}$ estimated that the intake of the sum of NDL-indicator PCB in children 
under 6 years of age at the mean and P95 fish consumption levels was $16 \cdot 1$ and $33.8 \mathrm{ng} / \mathrm{kg}$ per d, respectively. In children and adolescents under 12 years of age, the NDL-PCB intake at the mean and P95 was 24.6 and 60.0 $\mathrm{ng} / \mathrm{kg}$ per d, respectively. From this same study, in adolescents (over 12 years old) and adults, the NDL-PCB intake was 10.9 and $23.8 \mathrm{ng} / \mathrm{kg}$ per d, respectively, at the mean and $\mathrm{P} 95$ levels of fish consumption. Compared with our study, average fish consumers do not exceed these values. The intake data corresponding to other children have a value of $5.33(\mathrm{LB})$ and $1.80(\mathrm{UB}) \mathrm{ng} / \mathrm{kg}$ per $\mathrm{d}$ at $\mathrm{P} 50$ and 21.94 (LB) and 7.39 (UB) $\mathrm{ng} / \mathrm{kg}$ per $\mathrm{d}$ at P95. In adults, the estimated values in our study are 4.72 (LB) and 1.59 (UB) $\mathrm{ng} / \mathrm{kg}$ per $\mathrm{d}$ at $\mathrm{P} 50$ and 14.72 (LB) and 4.95 (UB) $\mathrm{ng} / \mathrm{kg}$ per $\mathrm{d}$ at P95.

In the case of France, two studies have been carried out. In the study by Arnich et al. ${ }^{(33)}$ conducted in 2009, the sum of NDL-PCB indicators in children at the mean and P95 levels of fish consumption was 12.9 and $27.3 \mathrm{ng} / \mathrm{kg}$ per $\mathrm{d}$, respectively. In the case of adults, the corresponding values were 7.7 and $16.0 \mathrm{ng} / \mathrm{kg}$ per d. Values in Arnich et al.'s study are slightly higher than those estimated in our study, which makes sense because other components in the diet that can provide NDL-PCB were analysed. In the study by Sirot et ll $^{(34)}$ carried out in 2012, the sum of NDL-indicator PCB in children at the mean and P95 fish consumption levels was 3.77 and $11.7 \mathrm{ng} / \mathrm{kg}$ per d, respectively. On the other hand, the corresponding values in adults decreased to 2.71 and $7.90 \mathrm{ng} / \mathrm{kg}$ per $\mathrm{d}$. These latter intake values of NDL-PCB are lower than those in Arnich $e t a l .{ }^{(33)}$ and the UB levels for adults in our study exceed them.

In Germany, in the study by Fromme et al. ${ }^{(35)}$ conducted in 2009, the average intake of the sum of NDL-PCB indicators in adults was $5.6 \mathrm{ng} / \mathrm{kg}$ per d. This value is above those we found at the $\mathrm{P} 50$ of adult fish consumers ( 4.72 and $1.59 \mathrm{ng} / \mathrm{kg}$ per d) but lower than those we estimated for the P95 of adult fish consumers (14.72 and $4.95 \mathrm{ng} / \mathrm{kg}$ per d).

In the Slovak Republic, Salgovicová and Pavlovicová $^{(36)}$ conducted a general population study in 2007 that estimated the intake of the sum of NDL-PCB indicators at the P50 and P95 levels of fish consumption as 17.0 and $45.0 \mathrm{ng} / \mathrm{kg}$ per d, respectively. In this case, the values exceed our estimated intakes in all consumers when fish with a medium concentration of NDL-PCB are consumed but are below our estimated levels when fish with a high concentration of NDL-PCB are consumed.

Finally, the European Food Safety Authority ${ }^{(8)}$ conducted a study for the general population in Europe in 2005, which estimated the intake of the sum of indicators of NDL-PCB at $15 \mathrm{ng} / \mathrm{kg}$ per $\mathrm{d}$ for the average consumer, $20 \mathrm{ng} / \mathrm{kg}$ per $\mathrm{d}$ for high meat consumers and $35 \mathrm{ng} / \mathrm{kg}$ per $\mathrm{d}$ for high fish consumers. Comparing the intakes estimated in the present study with the one carried out by the European Food Safety Authority ${ }^{(8)}$, our estimated values are below the latter ones except for high consumers of fish with a high concentration of NDLPCB (toddlers, 346.71 and $321.66 \mathrm{ng} / \mathrm{kg}$ per d; other children, 84.19 and $78.10 \mathrm{ng} / \mathrm{kg}$ per d; adolescents, 53.24 and $49.30 \mathrm{ng} / \mathrm{kg}$ per $\mathrm{d}$; adults, 56.46 and $52.38 \mathrm{ng} / \mathrm{kg}$ per d).

Our study results lead us to some possible indications for policies to improve food safety related to the presence of PCB in the fish consumed in our community. We recommend assiduous monitoring of the presence of PCB and the readjustment of the legislated safety levels since we identified populations at risk of exceeding the TDI, with the risk being between 0 and $34 \%$, although clearly the most vulnerable groups are the youngest ones in age. Therefore, the concentration values of PCB in fish with zero risk estimated in the results could serve as a guide for the establishment of new legally tolerated levels and other policies to provide greater food security.

We have to take into account that the fish analysed were raw fish. Therefore, if fish are not consumed raw, their content of PCB could vary: part of the fat may be lost and thus the PCB content may be reduced. Future studies on this subject should be carried out to assess if there is a change in the concentration of PCB in fish when cooked.

We have to consider the relative weight of fish consumption (\% of grams or \% of energy) within the whole diet of each population group, but this aspect has not been possible. We consider that studies on this topic would be of great importance in the assessment of the concentration of PCB from fish consumption in relation to total intake, as well as the proportion of PCB ingested through fish in relation to total PCB from other components of the diet in each population group.

It is expected that our values would be lower than all those estimated in the studies cited above since they studied the intake of NDL-PCB through the total diet and not only fish. It is important to note that despite our levels being inferior in most cases, there are some estimated intakes which are higher in our study, which implies that NDL-PCB have an important presence in the Spanish diet and it is necessary to have a special monitoring of these contaminants.

\section{Acknowledgements}

Acknowledgements: The authors wish to thank the University of Valencia and the Master's Degree in Environmental Pollution, Toxicology and Health. Financial support: This research received no specific grant from any funding agency in the public, commercial or not-for-profit sectors. Conflict of interest: None. Authorship: Authors' contributions were as follows. M.M.-S.-V.: Study design, 
data analysis, drafting the article, critical revision of the article, final approval of the version to be published. N.L.S.: Data collection, data analysis, drafting the article, final approval of the version to be published. P.M.R.: Data collection, data analysis, critical revision of the article, final approval of the version to be published. M.I.B.S.: Data collection, data analysis, final approval of the version to be published. I.P.-C.: Drafting the article, critical revision of the article, final approval of the version to be published. A.L.-G.: Study design, data analysis, critical revision of the article, final approval of the version to be published. Ethics of buman subject participation: Not applicable.

\section{References}

1. Gil A \& Gil F (2015) Fish, a Mediterranean source of $n$-3 PUFA: benefits do not justify limiting consumption. BrJ Nutr 113, Suppl. 2, S58-S67.

2. Bang HO \& Dyerberg J (1972) Plasma lipids and lipoproteins in Greenlandic west coast Eskimos. Acta Med Scand 192, 85-94.

3. Simmer K (2001) Long-chain polyunsaturated fatty acid supplementation in infants born at term. Cochrane Database Syst Rev issue 4, CD000376.

4. Lewin GA, Schachter HM, Yuen D et al. (2005) Effects of Omega-3 Fatty Acids on Child and Maternal Health: Summary. Rockville, MD: Agency for Healthcare Research and Quality.

5. Rangel-Huerta OD, Aguilera CM, Mesa MD et al. (2012) Omega-3 long-chain polyunsaturated fatty acids supplementation on inflammatory biomarkers: a systematic review of randomised clinical trials. Br J Nutr 107, Suppl. 2, S159-S170.

6. US Environmental Protection Agency (2013) Polychlorinated Biphenyls (PCB) Inspection Manual. https:// www.epa.gov/compliance/polychlorinated-biphenyls-pcbinspection-manual (accessed December 2017).

7. Jones KC \& de Voogt P (1999) Persistent organic pollutants (POPs): state of the science. Environ Pollut 100, 209-221.

8. European Food Safety Authority (2005) Opinion of the Scientific Panel on contaminants in the food chain on a request from the Commission related to the presence of non dioxin-like polychlorinated biphenyls (PCB) in feed and food. EFSA J 3, 284.

9. Lauby-Secretan B, Loomis D, Grosse Y et al. (2013) Carcinogenicity of polychlorinated biphenyls and polybrominated biphenyls. Lancet Oncol 14, 287-288.

10. International Agency for Research on Cancer (1987) IARC Monographs on the Evaluation of the Carcinogenic Risk to Humans. Overall Evaluations of Carcinogenicity: An Updating of IARC Monographs Volumes 1 to 42. Supplement 7. http://monographs.iarc.fr/ENG/Monographs/ suppl7/index.php (accessed December 2017).

11. World Health Organization (1998) Executive Summary: Assessment of the Health Risk of Dioxins: Re-evaluation of the Tolerable Daily Intake (TDI). Geneva: WHO.

12. Ribas-Fitó N, Sala M, Kogevinas M et al. (2001) Polychlorinated biphenyls (PCBs) and neurological development in children: a systematic review. I Epidemiol Community Health 55, 537-546.

13. Jacobson JL \& Jacobson SW (1996) Intellectual impairment in children exposed to polychlorinated biphenyls in utero. $N$ Engl J Med 335, 783-789.

14. Nakajima S, Saijo Y, Kato S et al. (2006) Effects of prenatal exposure to polychlorinated biphenyls and dioxins on mental and motor development in Japanese children at 6 months of age. Environ Health Perspect 114, 773-778.

15. Smith BJ (1982) PCB Levels in Human Fluids: Sheboygan Cohort Study, Sheboygan Maternal/Infant PCB Study. Madison, WI: University of Wisconsin.

16. Fischbein A, Thornton J, Wolff MS et al. (1982) Dermatological findings in capacitor manufacturing workers exposed to dielectric fluids containing polychlorinated biphenyls (PCBs). Arch Environ Health Int J 37, 69-74.

17. Emmett EA, Maroni M, Jefferys J et al. (1988) Studies of transformer repair workers exposed to PCBs: II. Results of clinical laboratory investigations. Am J Ind Med 14, 47-62.

18. Tryphonas H, Hayward S, O'Grady L et al. (1989) Immunotoxicity studies of PCB (Aroclor 1254) in the adult rhesus (Macaca mulatta) monkey - preliminary report. Int J Immunopharmacol 11, 199-206.

19. Tryphonas H, Luster MI, Schiffman G et al. (1991) Effect of chronic exposure of PCB (Aroclor 1254) on specific and nonspecific immune parameters in the rhesus (Macaca mulatta) monkey. Fundam Appl Toxicol 16, 773-786.

20. Arnold DL, Bryce F, Stapley R et al. (1993) Toxicological consequences of Aroclor 1254 ingestion by female rhesus (Macaca mulatta) monkeys. Part 1A. Prebreeding phase: clinical health findings. Food Chem Toxicol 31, 799-810.

21. Arnold DL, Bryce F, Karpinski K et al. (1993) Toxicological consequences of Aroclor 1254 ingestion by female rhesus (Macaca mulatta) monkeys. Part 1B. Prebreeding phase: clinical and analytical laboratory findings. Food Chem Toxicol 31, 811-824.

22. European Food Safety Authority (2017) The EFSA Comprehensive European Food Consumption Database. https:// www.efsa.europa.eu/en/food-consumption/comprehen sive-database (accessed December 2017).

23. European Commission (2012) Commission Regulation (EU) No. 252/2012 of 21 March 2012 laying down methods of sampling and analysis for the official control of levels of dioxins, dioxin-like PCBs and non-dioxin-like PCBs in certain foodstuffs and repealing Regulation (EC) No. 1183/2006 (Text with EEA relevance). Official Journal of the European Union L84, 23.3.2012, 1-22.

24. Cocco E, Guignard C, Hoffmann L et al. (2011) Rapid analysis of polychlorinated biphenyls in fish by pressurised liquid extraction with in-cell cleanup and GC-MS. Int $J$ Environ Anal Chem 91, 333-347.

25. Nikonova AA \& Gorshkov AG (2011) Rapid chromatography for the determination of polychlorinated biphenyls by GC-MS in environmental monitoring. Anal Lett $\mathbf{4 4}$, 1290-1300.

26. European Commission (2017) Commission Regulation (EU) No. 2017/644 of 5 April 2017 laying down methods of sampling and analysis for the control of levels of dioxins, dioxin-like PCBs and non-dioxin-like PCBs in certain foodstuffs and repealing Regulation (EU) No. 589/2014 (Text with EEA relevance). Official Journal of the European Union L92, 6.4.2017, 1-26.

27. Food and Agriculture Organization of the United Nations, Fisheries and Aquaculture Department (2017) Fishery Statistical Collections I Consumption of Fish and Fishery Products. http://www.fao.org/fishery/statistics/glo bal-consumption/en (accessed December 2017).

28. Ministerio de Agricultura y Pesca, Alimentación y Medio Ambiente (2017) Base de datos de consumo en hogares. http://www.mapama.gob.es/es/alimentacion/temas/ consumo-y-comercializacion-y-distribucion-alimentaria/ panel-de-consumo-alimentario/base-de-datos-de-consumoen-hogares/consulta.asp\# (accessed December 2017).

29. Schantz SL, Widholm JJ \& Rice DC (2003) Effects of PCB exposure on neuropsychological function in children. Environ Health Perspect 111, 357-576. 
30. Winneke G, Walkowiak J \& Lilienthal H (2002) PCBinduced neurodevelopmental toxicity in human infants and its potential mediation by endocrine dysfunction. Toxico$\operatorname{logy}$ 181-182, 161-165.

31. Kodavanti PR, Ward TR, Derr-Yellin EC et al. (1998) Congener-specific distribution of polychlorinated biphenyls in brain regions, blood, liver, and fat of adult rats following repeated exposure to Aroclor 1254. Toxicol Appl Pharmacol 153, 199-210.

32. Fattore E, Fanelli R, Dellatte E et al. (2008) Assessment of the dietary exposure to non-dioxin-like PCBs of the Italian general population. Chemosphere 73, 1 Suppl., S278-S283.

33. Arnich N, Tard A, Leblanc J-C et al. (2009) Dietary intake of non-dioxin-like PCBs (NDL-PCBs) in France, impact of maximum levels in some foodstuffs. Regul Toxicol Pharmacol 54, 287-293.

34. Sirot V, Tard A, Venisseau A et al. (2012) Dietary exposure to polychlorinated dibenzo- $p$-dioxins, polychlorinated dibenzofurans and polychlorinated biphenyls of the French population: results of the second French total diet study. Chemosphere 88, 492-500.

35. Fromme H, Shahin N, Boehmer S et al. (2009) Dietary intake of non-dioxin-like polychlorinated biphenyls (PCB) in Bavaria, Germany. Results from the Integrated Exposure Assessment Survey (INES). Gesundheitswesen 71, 275-280.

36. Salgovicová D \& Pavlovicová D (2007) Exposure of the population of the Slovak Republic to dietary polychlorinated biphenyls. Food Chem Toxicol 45, 1641-1649. 